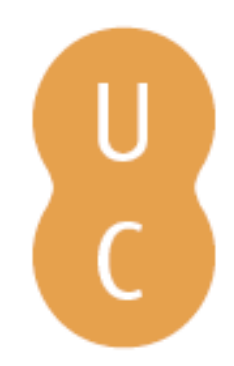

\title{
nommalina
}

\section{"Que mulher não é freira?": a religião como instrumento político para a submissão das mulheres}

\author{
Autor(es): $\quad$ Toldy, Teresa Martinho \\ Publicado por: Imprensa da Universidade de Coimbra \\ URL \\ persistente: URI:http://hdl.handle.net/10316.2/42352 \\ DOI: $\quad$ DOI:https://doi.org./10.14195/978-989-26-1308-6_40 \\ Accessed : $\quad$ 26-Apr-2023 11:59:26
}

A navegação consulta e descarregamento dos títulos inseridos nas Bibliotecas Digitais UC Digitalis, UC Pombalina e UC Impactum, pressupõem a aceitação plena e sem reservas dos Termos e Condições de Uso destas Bibliotecas Digitais, disponíveis em https://digitalis.uc.pt/pt-pt/termos.

Conforme exposto nos referidos Termos e Condições de Uso, o descarregamento de títulos de acesso restrito requer uma licença válida de autorização devendo o utilizador aceder ao(s) documento(s) a partir de um endereço de IP da instituição detentora da supramencionada licença.

Ao utilizador é apenas permitido o descarregamento para uso pessoal, pelo que o emprego do(s) título(s) descarregado(s) para outro fim, designadamente comercial, carece de autorização do respetivo autor ou editor da obra.

Na medida em que todas as obras da UC Digitalis se encontram protegidas pelo Código do Direito de Autor e Direitos Conexos e demais legislação aplicável, toda a cópia, parcial ou total, deste documento, nos casos em que é legalmente admitida, deverá conter ou fazer-se acompanhar por este aviso.

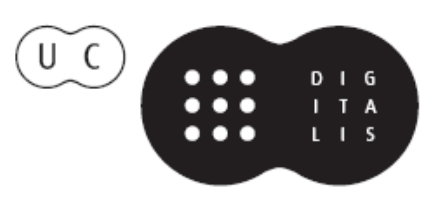





\title{
“QUE MULHER NÃO É FREIRA?" A RELIGIÃO COMO INSTRUMENTO POLÍTICO PARA A S UBMISSÃO DAS MULHERES
}

\author{
Teresa Martinbo Toldy
}

Em meu entender, o discurso poético não é poético se não for um discurso de resistência, ou seja, um discurso que, embora sem qualquer poder para fazer coisas acontecerem, interrompe a língua convencional e institucionalizada que nos fala a vida, a realidade e a existência em geral e, ao fazê-lo, coloca-a radicalmente em questão.

Maria Irene Ramalbo ${ }^{2}$

Resumo: Em 1969, Carol Hanisch escreveu um texto no qual reagia à crítica dos movimentos radicais (sobretudo marxistas) àquilo que estes consideravam ser apenas "um efeito terapêu-

${ }^{1}$ Este texto foi apresentado no Colóquio Internacional "Novas Cartas, Novas Cartografias: Re-configurando Diferenças no Mundo Globalizado”, ocorrido entre 13 e 15 de Março de 2014 na Universidade de Évora.

2 Discurso da Conferência Plenária do II Simposio EDiSo (18 junho 2015). Web. 14.07.2015. 
tico" dos grupos de mulheres reunidas para discutirem o seu quotidiano (os chamados grupos de "consciousness raising"). O slogan "the personal is political" passou a traduzir a compreensão da necessidade e da relevância de desmontar os mecanismos de poder (também religiosos, embora estes não sejam nomeados por Carol Hanisch) reproduzidos no mundo "privado", dito "das mulheres". "Que mulher não é freira?" - esta pergunta, colocada nas Novas Cartas Portuguesas, sintetiza de forma magistral o papel desempenhado pela religião na legitimação do enclausuramento das mulheres. $O$ presente texto visa identificar os mecanismos religiosos deste enclausuramento enquanto eco e fundamento de uma ordem social na qual a submissão das mulheres constituía um pilar central.

Palavras-chave: religião; patriarcado; literatura; mulheres; política.

Abstract: Carol Hanisch wrote a text in 1969 in which she reacts against the critical attitude of radical movements (especially Marxist movements) towards what they consider to be a "therapeutic effect" of women's groups gathered to talk about women's day to day life (the so called "consciousness raising groups"). The slogan "the personal is political" translates the awareness of the need and relevance of deconstructing mechanisms of power (also religious, although Hanisch makes no reference to them in her text) replicated in the "private world" - the "women's word". "What woman is not a nun?" - the question asked by Novas Cartas Portuguesas (New Portuguese Letters) represents a masterful synthesis of the role played by religion in the legitimization of this "cloistering" of women. This text aims to identify the religious mechanisms 
of this cloistering as echo and basis of a social order in which submission of women constituted a central pillar.

Keywords: religion; patriarchy; literature; women; politics.

\section{1. "The personal is political"}

Em 1969, Carol Hanisch escrevia um texto intitulado "The Personal Is Political", no qual reagia à crítica dos movimentos radicais (sobretudo marxistas) a um certo efeito, considerado pelos mesmos como apenas "terapêutico", de grupos de mulheres reunidas para discutirem o seu quotidiano (os chamados "consciousness raising groups"). Em 2006, na releitura que faz do seu próprio texto, Hanisch, referindo-se concretamente à ação e ao pensamento da organização Southern Conference Educational Fund, à qual pertencera, nos anos 70 , e que centrava o seu ativismo na luta pelos direitos civis no Sul dos EUA, afirma o seguinte:

. . muitos dos membros do SCEF, tanto homens como mulheres, associavam-se à crítica que considerava a reunião das mulheres em grupos de consciencialização, para discutirem a sua própria opressão, como algo "egocêntrico" e como "terapia pessoal", - e certamente como algo "não político". Por vezes, admitiam que as mulheres eram oprimidas (mas apenas pelo "sistema") e diziam que devíamos ter salário igual para trabalho igual e mais alguns "direitos". Mas minimizavam-nos por tentarmos trazer os nossos "problemas pessoais" para a arena pública - especialmente "essas coisas todas do corpo", como o sexo, a aparência e o aborto. As nossas exigências de que os homens partilhassem a lida da casa e o cuidado das crianças também 
eram consideradas um problema pessoal, entre uma mulher e o seu marido. A oposição afirmava que, se as mulheres "se defendessem elas próprias" e assumissem mais responsabilidade pelas suas próprias vidas, não precisariam de ter um movimento independente para a libertação das mulheres. Diziam que o que a iniciativa pessoal não resolvesse seria assumido pela "revolução", desde que nos calássemos e fizéssemos a nossa parte. Deus nos livrasse de denunciar que os homens beneficiavam da opressão das mulheres! (Hanisch 2006: 1)

Ora, segundo Hanisch, o que o slogan the personal is political pretende enfatizar é precisamente a existência de uma articulação entre o pessoal e o político. Antes de mais, porque tomar a palavra num processo de consciencialização significa dizer-se a si própria, em vez de se deixar dizer por outros ou de repetir os papéis que a sociedade atribui às mulheres. Depois, porque os problemas pessoais são problemas políticos de dois pontos de vista articulados entre si: primeiro, "neste momento, não há soluções pessoais" (escrevia Hanisch em 1969) - "Só existe uma ação colectiva para uma solução colectiva"; em segundo lugar, porque, nos problemas ditos "pessoais" e "privados", se reflete uma ordem social de subalternização das mulheres. Daí que, para Hanisch, não seja justo considerar os grupos de consciencialização como uma "terapia”, a menos, segundo ela, que estes sejam considerados uma "terapia política", isto é, uma libertação de mecanismos de auto-culpabilização, um processo de rebelião e de empowerment, e um reconhecimento político de que "women are messed over, not messed up!” (Hanisch 1969).

O que os grupos de consciencialização pretendiam era, pois, nas palavras de Mary Nash (172), "quebrar o silêncio, encontrar a sua voz e verbalizar os seus problemas." Por isso, “a verbalização e a expressão da opressão doméstica foram um passo crucial no desen- 
volvimento das primeiras fases do MLM internacional." Nestes grupos discutiam-se as questões da sexualidade, do controlo da natalidade, das partilhas de poder na família. Eram grupos que pretendiam quebrar o isolamento das mulheres e criar um espaço de sintonia e de liberdade de expressão, "A Room of One‘s Own", como diria Virginia Woolf (1928), um espaço de diferença. Estes grupos foram fundamentais para a emergência da categoria da experiência, tanto do ponto de vista sociológico, como cultural, isto é, como processo de atribuição de significado ao quotidiano privado e como ponto de partida para a emancipação. E, acrescenta Mary Nash (175), "ao contrário do feminismo histórico, que questionou as práticas de poder formal discriminatório de instituições e de governos, o MLM identificou o homem como agressor em casa”. A libertação da mulher voltou-se para a transformação do espaço das relações privadas. "Esta visão significava, portanto, que se considerava que o exercício do predomínio masculino patriarcal se localizava em casa e era exercido através das relações estreitas e afectivas entre a mulher e o seu opressor" (ibidem).

As Novas Cartas Portuguesas, de 1974, 3 constituem, precisamente, um exemplo acabado desta necessidade, desta vontade e desta concretização do quebrar do silêncio, da verbalização revolucionária dos mecanismos (públicos e privados!) de poder patriarcal, ao desmontarem o quotidiano privado (e também público!) das mulheres como um espaço de submissão e de enclausuramento, pois "há sempre uma clausura pronta a quem levanta a grimpa contra os usos" (NCP: 13). Como se escreve na Terceira Carta IV (a longa citação justifica-se pela síntese que faz do debate que acabei de mencionar!),

Inevitavelmente, passámos de amor à história e à política, e aos mitos que calçam circunstâncias históricas e políticas, e tu

3 Citado a partir daqui com a sigla NCP. 
perguntaste "é o pacto com o demónio que sugeres?" E não foi por acaso essa pergunta - de fora nos julgamos, mas são nossos temores mais fundos o que nos liga ao que rejeitamos - como não é acaso ser o demónio homem preto, ou vermelho, ou tomar forma feminina, no dicionário dos bruxedos; demónio é o anjo caído por ter ameaçado a ordem superiormente estabelecida. Passamos assim aos mitos de circunstâncias históricas e políticas, porque não nos é possível ainda, falar em amor; porque na relação a dois, homem e mulher julgando-se sós e nos seus sexos, se vem imiscuir o que a sociedade fez e exige de cada um; porque relação a dois, e não só no casamento, é mesmo base política do modelo da repressão; porque se mulher e homem se quiserem sós e nos seus sexos, logo isso é sabido como ataque à sociedade que só junta para dominar, e Abelardo é castrado, e Tristão nunca se junta a Isolda, e todos os mitos do amor dão-no como impedido e irrealizado, e todas as histórias de amor são histórias de suicidas; porque temos de remontar o curso da dominação, desmontar suas circunstâncias históricas, para destruir suas raízes. Entendo, pois, que não basta pensar em relações de produção, sendo socialmente a mulher produtora de filhos e vendendo sua força de trabalho ao homem-patrão. Esta é uma exacta e muito necessária, mas não total leitura da realidade; necessária por bem agarrar este fulcro da questão, talvez até sua origem histórica, e que tanto se quer escamotear na arengada promoção da mulher. Mas a esta leitura é necessário acrescentar todos os sistemas de cristalizações culturais que vieram sustentando, reforçando, justificando e ampliando essa dominação da mulher (e não só essa dominação), porque a alteração da situação económica e política que agora nela se baseia não traz necessariamente a destruição de todas as cristalizações culturais em que a mulher é imbecil jurídica, irresponsável social, homem castrado, a carne, a pecadora, Eva da serpente, corpo sem alma, virgem-mãe, bruxa, mãe abnegada, vampiro do 
homem, fada do lar, ser humano estúpido e muito envergonhado pelo sexo, cabra e anjo, etc., etc. E digo é tudo isto no presente, porque contra estas imagens nunca houve combate de raiz, apenas se foram pondo em causa as consequências lógicas e práticas de algumas delas, na medida em que já não convêm, já não servem mais ao homem. .." (NCP: 102-104)

É nesta linha, que as Novas Cartas Portuguesas começam a puxar (cf. 106), que não só "se ensopam e mitificam" as "nossas políticas, nossas éticas, nossos amores a dois" (idem), mas também emerge a religião, não referida - diga-se! - no mencionado texto de Hanisch - matricial para a consciência de que "the personal is political", mas com um lugar de destaque nas Novas Cartas Portuguesas, que, glosando os temas das cartas de Soror Mariana Alcoforado, equiparam a vida de todas as mulheres à vida de uma freira num convento: "Que mulher não é freira, oferecida, abnegada, sem vida sua, afastada do mundo?" (NCP: 177).

\section{2. "Que mulher não é freira?"}

O entrelaçamento da opressão privada com a exclusão pública no sistema patriarcal é equiparado, portanto, à vida de clausura. A pergunta - "que mulher não é freira?" - transporta-nos, antes de mais, para uma crítica de um sistema de encerramento das mulheres no espaço privado e, afinal, também, no espaço público: já que o objetivo consiste em excluir, simultaneamente, as mulheres deste último, invisibilizando-as, e reproduzir no espaço privado a mesma ordem que as exclui do público. Por isso, nas Novas Cartas Portuguesas, o reverso deste enclausuramento passa pela subversão do privado: "Ninguém me peça, tente, exija, que regresse à clausura dos outros" (NCP: 47). 
A metáfora do convento aparece para evocar diversas facetas da opressão a que as mulheres estão sujeitas. O próprio homem é apresentado como um convento, estabelecendo-se um paralelo entre a posse da mulher e a posse da terra, como se, em ambos os casos, se tratasse de uma colónia, num espaço enclausurado e enclausurante (cf. NCP: 29).

De enclausuramento se fala também a propósito da submissão à "mui ubíqua lei do pai" (como diria Luisa Valenzuela 23), aquela lei que, na Carta de Mariana Alcoforado a sua Mãe (nas Novas Cartas Portuguesas), leva Mariana a identificar o convento com o seu túmulo, por ser o lugar em que se encontra à mercê desta lei patriarcal: "Bem me podeis executar, quem me defende? A lei? A que dá aos pais todos os direitos de mordaça, aos machos primazia e à mulher somente o infinitamente menos nada, com dádivas de tudo?" (NCP: 68).

E é também através da metáfora do convento que, na sequência intitulada "A freira ensanguentada", as Novas Cartas Portuguesas falam da "irmandade no convento", das diversas formas de traição a que são sujeitas pelos homens, quer sejam "freiras em convento" ou "dadas em casamento", já que, apesar de os homens se dividirem em "homens e senhores" (NCP: 80), "das mulheres todos os homens são senhores" (ibidem) e a elas, só lhes resta o convento, já que não possuem nem casa, nem irmão, nem irmã - "vendidas" que são de si próprias (cf. ibidem), pois "não houve pão" para elas "à mesa dos homens" (ibidem). Tanto casadas, como monjas, "a desgraça" das mulheres é a mesma: vivem numa clausura à força - a umas, foi dado marido; a outras, grades e muros. Se bem que, na carta de D. Joana de Vasconcelos para Mariana Alcoforado, se considere pior a sina de casada do que a de freira enclausurada:

As grades e os muros desse convento impedem-te os passos, a ferros te puseram, mas assim te deixaram sem disso darem conta, 
liberdade de te imaginares, de viveres contigo própria, enquanto eu todos os dias me violento nos outros, neles, com eles me obrigando a usos e maneiras que me repugnam vivamente, bem o sabes, que só forçada sou objecto ou enfeite. (NCP: 171-172)

E conclui D. Joana: "monja me agradaria mais ser que mulher odiando seu marido" (172). "Que mais nos espera ainda, embora morta tu em tua cela e eu morta em meu quarto?” (173).

Não se pense, contudo, que, nas Novas Cartas Portuguesas, a religião aparece associada apenas à metáfora do enclausuramento. O texto desliza das referências metafóricas para referências políticas à situação das mulheres sob o peso de formas opressivas de religião, baseando nela o fio de uma meada que vem das cartas de Mariana até à "redação de uma rapariga de nome Maria Adélia nascida no Carvalhal e educada num asilo religioso em Beja", passando por uma legitimação das tarefas dos homens e das mulheres, baseada, supostamente, na própria religião. Esse texto é revelador da ideologia da época em que as Novas Cartas foram redigidas no que diz respeito à "ordem das coisas", como veremos.

A redação intitula-se "As tarefas". Depois de afirmar que há tarefas do homem e tarefas da mulher, Maria Adélia descreve as tarefas de um e outro. Assim, as do homem são "aquelas da coragem, da força e do mando. Quer dizer: serem presidentes, generais, serem padres, soldados caçadores, serem toureiros, serem futebolistas e juízes” (NCP: 289). Estas tarefas do homem resultam da própria vontade de Deus, que lhes deu "a tarefa de velar e mandar, que até Jesus Cristo foi homem e Deus escolheu ter filho e não filha para morrer neste mundo em desconto dos nossos pecados" (ibidem). A ordem patriarcal da salvação justifica, portanto, que sejam os homens a organizar as guerras "para tirarem o mundo da perdição e do pecado (por exemplo: as cruzadas), combatendo para salvar a Pátria e defender assim as mulheres, as crianças e os velhos" (ibidem). 
Quando às tarefas das mulheres, "acima de todas está a de ter filhos, guardá-los e tratá-los nas doenças, dar-lhes a educação em casa e o carinho; é também tarefa da mulher ser professora e mais coisas, tal como costureira, criada, enfermeira" (289-290). Maria Adelaide menciona que "há também mulheres médicas, engenheiras, advogadas, etc." (290). Contudo, a "lei do pai" diz-lhe que "é melhor a gente não se fiar nelas" (ibidem), uma vez que fogem ao seu destino:

as mulheres foram feitas para a vida da casa, que é uma tarefa muito bonita e dá muito gosto ter tudo limpo e arrumado para quando chegar o nosso marido ele poder descansar do trabalho do dia que foi tanto, a fim de arranjar dinheiro para nos sustentar e aos filhos. (ibidem)

E se tudo assim é e deve ser, também é por vontade de Deus, como diz Maria Adelaide: "O mundo sempre foi assim, prega o Senhor Prior" (292). Isto é, o mundo está dividido, segundo o plano de Deus (transmitido pelo Senhor Prior), entre homens e mulheres, tarefas de homens e tarefas de mulheres, mas também entre "tarefas dos ricos" ("serem caridosos") e "tarefas dos pobres" ("pedir e aceitar o que lhes dão mostrando-se muito agradecidos") (292), "tarefas dos patrões" ("castigar os empregados") e dos "empregados" ("trabalhar para os patrões a fim de estes ficarem mais ricos e mais patrões") (293). Contudo, Maria Adélia constata que o pai, apesar de não ser patrão no emprego, "quando vem bêbedo e bate na mãe, grita: aqui eu é que sou o patrão!" (ibidem), reproduzindo-se, assim, dentro de casa a ordem de mando do patrão sobre o empregado.

Depois de descritas todas estas tarefas, Maria Adélia tem só duas dificuldades: uma delas é perceber em que consiste a tarefa "da mulher de má vida" (ibidem), acerca da qual o Senhor Prior diz "ser 
tal coisa grande pecado e qualquer mulher que tenha essa tarefa vai para o inferno. .." (ibidem). A outra dificuldade é perceber o que é a tarefa, mencionada pelo Senhor Prior, de "ser virtuosa". Embora não saiba do que se trata, Maria Adélia conclui: "imagino que não deve dar nenhum arranjo" (294).

A ironia corrosiva deste texto transmite quase ipsis verbis a ideologia de género do Estado Novo e a fundamentação da mesma numa interpretação da religião como parte da trilogia "Deus, Pátria, Autoridade". Isabel Freire, no seu livro intitulado Amor e sexo no tempo de Salazar, cita abundantemente textos da época nos quais se repete à saciedade que o lugar da mulher é em casa e que isto corresponde à vontade de Deus. Cito aqui apenas três exemplos da ideologia da época. Primeiro exemplo, de 1938: "A 'Lição de Salazar" - uma série de cartazes com o objectivo de promover os valores centrais do Estado Novo. O último cartaz tem precisamente o título: "Deus, Pátria, Família: A trilogia da educação nacional". Verónica Policarpo comenta-o assim:

$\mathrm{Na}$ imagem observamos um lar perfeito, humilde, rural, patriarcal e cristão que celebra a vida simples e sem vícios do campo. O pai, chefe de família, chega do trabalho no campo para o repouso num lar pobre, sem água nem electricidade, sem livros ou aparelhos de rádio. Encontra a esposa que, ligeiramente curvada, se ocupa das lides da casa e os filhos que o saúdam: a filha brincando com uma boneca, o filho com a farda da Mocidade Portuguesa. Sobressaem o crucifixo que ocupa lugar de destaque e, na mesa já posta para a refeição, os alimentos simples, como o pão e o vinho. (idem: v)

Segundo exemplo: um texto da Crónica Feminina de 1957 (cit. in Freire 188-189). Trata-se de uma espécie de mandamentos para a felicidade no lar ("Dez Mandamentos" - como compete!): 
1 - Ame o seu marido acima de todas as coisas [note-se o paralelo com o $1 .^{\circ}$ mandamento bíblico: "Amar a Deus acima de todas as coisas!]; . . . lembre-se que a sua casa pertence a seu marido e não ao seu próximo.

2 - Considere o seu marido como um convidado selecto, como um amigo precioso, e não como uma amiga, a quem se contam as pequenas futilidades da vida. Evite essa amiga, caso the seja possível.

3 - Mantenha a sua casa bem arrumada e ostente uma cara risonha quando o seu amigo chegar, no entanto, quando vir que ele não repara nela, deve desculpá-lo.

4 - Nunca peça nada a seu marido, daquilo que ele não the pode oferecer, dê graças a Deus, por possuir uma casa alegre, ar livre, e a felicidade para os seus filhos.

5 - Que os seus filhos estejam bem arranjados e limpos, assim como a sua pessoa. .

6 - Lembre-se que o desposou para o acompanhar na riqueza e na pobreza [invocação das palavras do ritual litúrgico do casamento!], devendo pegar-lhe na mão carinhosamente se todos o abandonarem.

7 - Se o seu marido ainda tiver mãe, lembre-se que deve ser boa e dedicada para ela, pois foi ela quem o acarinhou, enquanto criança.

8 - Nunca exija da vida o impossível; já deve sentir-se feliz se tiver algum préstimo.

9 - Se surge algum azar, não se deixe levar pelo desespero; a calma voltará, se confiar em seu marido, o qual, assim, terá coragem para lutar pelos dois;

10 - Se o seu marido se afastar de si, espere-o; ainda mesmo que ele a abandone; espero sempre por ele, porque, não só é esposa dele, como também representa o seu nome, a sua honra; um dia ele voltará, abraçando-a. 
Terceiro exemplo: um outro texto da mesma revista - Crónica Feminina (1958):

Defende o teu lar! Se o teu marido te auxiliar na criação do bebé, embora essa iniciativa seja do teu agrado, não deves abusar dela. O facto de o teu marido te substituir às vezes, adormecendo a criança ou passeando-a no carrinho, não quer dizer que faças dessas complacências um hábito. Arriscar-te-ias a vê-lo subitamente irado. . Então, o marido irado declarou: Estou farto de te servir como amo! De hoje em diante, não contes comigo para dar o alimento à criança. Este trabalho compete às mães. (cit. in Aboim 95)

As concepções patentes nestes exemplos são perfeitamente consentâneas com a doutrina eclesiástica da época, que idealiza e prescreve a figura da mulher como uma mãe perfeita. Pio XII afirmava que "a mãe é o centro da vida quotidiana" da família, sempre atenta às suas necessidades e pronta para tornar os seus filhos felizes. Ela vem ao mundo com a missão de ser mãe, de espalhar a alegria em redor. Sem ela, "a casa arrefece; o lar deixa praticamente de existir". ${ }^{4}$

Os textos eclesiásticos partem destes pressupostos relativamente à mulher, pelo que todas as suas afirmações acerca da mesma constituem um desenvolvimento deste pensamento fundamental. A mulher é sempre encarada como mãe e como esposa em todos os domínios da vida. A associação da mulher ao domínio privado e do homem ao domínio público fundamenta-se na identificação pura e simples do papel sociocultural da mulher com a sua identidade biológica. A acentuação do papel materno da mulher, tal como os

${ }^{4}$ Cf. PIO XII., Audiência Geral, 24.02.1942, OR 47 (26 Fevereiro 1942) 1. Para uma noção global da doutrina eclesiástica sobre a mulher cf. Toldy (1998). 
textos do Magistério a fazem, constitui, portanto, uma justificação e uma perpetuação teológica de uma ordem social prescritiva. Como diz bell hooks (2004) falando da sua própria experiência:

Os nossos pais acreditavam no patriarcado; tinham-lhes ensinado a pensar de forma patriarcal através da religião. Na igreja tinham aprendido que Deus criara o homem para mandar no mundo e em tudo o que nele existe e que era tarefa das mulheres ajudarem os homens a desempenhar essa tarefa, obedecerem e assumirem sempre um papel subordinado em relação ao homem poderoso. Foi-lhes ensinado que Deus era homem. Estes ensinamentos eram reforçados pelas diversas instituições com as quais se depararam - escolas, tribunais, clubes, estádios e igrejas. Assumindo o pensamento patriarcal, como toda a gente à sua volta, eles ensinaram-no aos seus filhos, porque parecia uma forma 'natural' de organizar a vida. (17, tradução minha)

\section{3. "O patriarcado - uma pirâmide de opressões multiplicativas"}

Ora, de facto, o patriarcado "naturalizado" constitui uma "pirâmide de opressões multiplicativas", para utilizar a expressão de Elisabeth Schüssler Fiorenza. Quer isto dizer, que a ordem social baseada na "lei do pai” não só legitima a submissão das mulheres, como constitui, acima de tudo, uma estrutura complexa de opressões que, interseccionando-se, se potenciam mutuamente. Citando Deborah King (270), "as opressões simultâneas não são apenas múltiplas. São multiplicativas: o racismo multiplica-se pelo sexismo, multiplicado pelo 'ageism', multiplicado pelo classismo, multiplicado pela exploração colonial". Trata-se, pois, de "uma estrutura política piramidal e complexa de dominação e de subordinação, estratificada 
de acordo com o género, a raça, a classe, as taxonomias religiosas e culturais e outras formas de domínio ao longo da história" (Fiorenza 115). Deus, nesta perspectiva, aparece como a legitimação última de uma pirâmide de opressões multiplicativas: aparece como um homem, branco, do lado dos poderosos, do lado eurocêntrico. Este Deus perpassa todas as formas de enclausuramento identificadas nas Novas Cartas Portuguesas, no que elas têm de escrita de um pedaço da história das opressões públicas através do seu espelho nas repressões privadas. Por isso, "the personal is (indeed!) political", pois pode estilhaçar por dentro "a ordem do pai": realmente, "se a mulher se revolta contra o homem, nada fica intacto" (NCP: 182).

\section{Obras citadas}

Aboim, Isabel. "Vidas conjugais: do institucionalismo ao elogio da relação". Dir. José Mattoso. História da Vida Privada em Portugal. Os Nossos Dias. Coord. Ana Nunes de Almeida. Lisboa: Temas e Debates/Círculo dos Leitores, 2011. 80-111. Print.

Barreno, Maria Isabel, Maria Teresa Horta e Maria Velho da Costa. Novas Cartas Portuguesas. Lisboa: Editorial Futura, 1974. Print.

Fiorenza, Elisabeth Schüssler. But She Said. Feminist Practices of Biblical Interpretation. Boston: Beacon Press, 1992. Print.

Freire, Isabel. Amor e Sexo no Tempo de Salazar. Lisboa: A Esfera dos Livros, 2010. Print.

Hanisch, Carol [1969 e 2006]. "The Personal Is Political”. Web. 12.01.2014.

hooks, bell. The Will to Change: Men, Masculinity, and Love. Nova Iorque: Atria Books, 2004. Print.

King, Deborah. "Multiple Jeopardy, Multiple Consciousness: The Context of Black Feminist Ideology". Ed. M.R. Malson et al. Black Women in America: Social Science Perspectives. Chicago: Chicago University Press, 1990. 265-296. Print.

Nash, Mary. As Mulheres no Mundo. História, desafios e movimentos. Vila Nova de Gaia: Editora Ausência, 2004. Print.

Policarpo, Verónica. "Sexualidades em construção, entre o privado e o público”. Dir. José Mattoso. História da Vida Privada em Portugal. Os Nossos Dias. Coord. Ana Nunes de Almeida. Lisboa: Temas e Debates/Círculo dos Leitores, 2011. 48-79. Print.

Toldy, Teresa. Deus e a Palavra de Deus na Teologia Feminista. Lisboa: Edições Paulinas, 1998. Print. 
Valenzuela, Luisa. "Mujeres fuera de la Ley (del Padre)". Org. Toscano, Ana Maria da Costa. Mulheres Más. Percepção e Representações da Mulher transgressora no Mundo Luso-Hispânico: América Latina. Porto: Edições Universidade Fernando Pessoa, 2006. 20-29. Print.

Woolf, Virginia [1928]. A Room of One's Own. Londres: Penguin Books, 1945. Print. 